\title{
A clupeid fish can detect ultrasound
}

It has been suggested that most teleost fishes cannot detect sounds higher than 2 or $3 \mathrm{kHz}$ (ref. 1). However, we report here that at least one species of clupeid fish (herrings and shads), the American shad (Alosa sapidissima), can detect sounds up to 180 $\mathrm{kHz}$. We speculate that clupeids are able to detect the ultrasonic clicks of one of their major predators, echolocating cetaceans ${ }^{2}$.

Blueback herring swim away from echosounders, indicating that they may be able to detect ultrasound ${ }^{3}$, and ultrasound is used to keep several clupeids from entering water intakes of electric power-generating plants ${ }^{4}$. But it was not clear whether the fish were detecting the ultrasonic frequencies, or whether they were detecting lowerfrequency side-bands associated with the pulsed sounds.

To test the range of frequencies detected, we measured auditory thresholds of shad (Fig. 1) using a classical conditioning technique in which the fish learned to reduce their heart rate when they detected a sound (Fig. 2a $)^{5}$. We trained five fish using tones from 0.2 to $180 \mathrm{kHz}$ (Fig. 2b). Measurement of the frequency spectrum of the signal showed that the sound contained only pure tones.

American shad showed the greatest sensitivity to sounds between 0.2 and $0.8 \mathrm{kHz}$ (Fig. 2b). The thresholds were somewhat poorer at $1.6 \mathrm{kHz}$, with the worst sensitivity

a
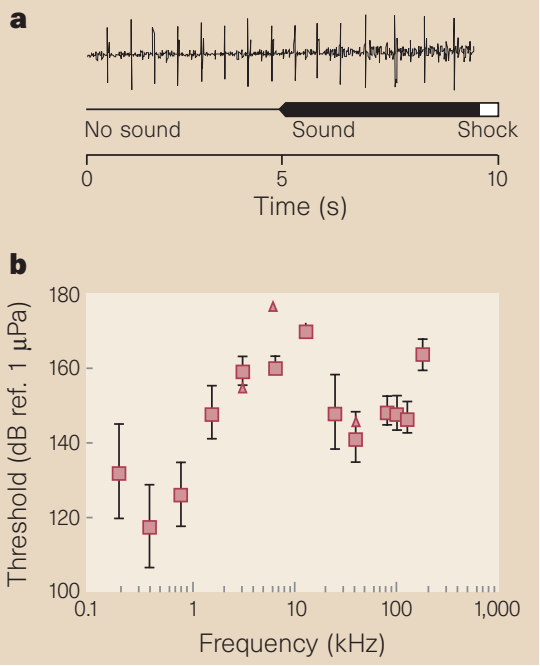

Figure 2 Ultrasonic detection by American shad. a, Example of cardiac responses to a $130-\mathrm{kHz}$ sound followed immediately with a mild electric shock. After a 5-s control period with no sound, a tone was played for $5 \mathrm{~s}$ ending with an electrical shock. Individual spikes are heartbeats, which slow down in the presence of the sound and before the shock. b, Audiogram. Squares are means \pm s.e.m., $N=5$. Triangles represent mean maximum amplitudes produced by the system at which some fish were unable to detect the sound.

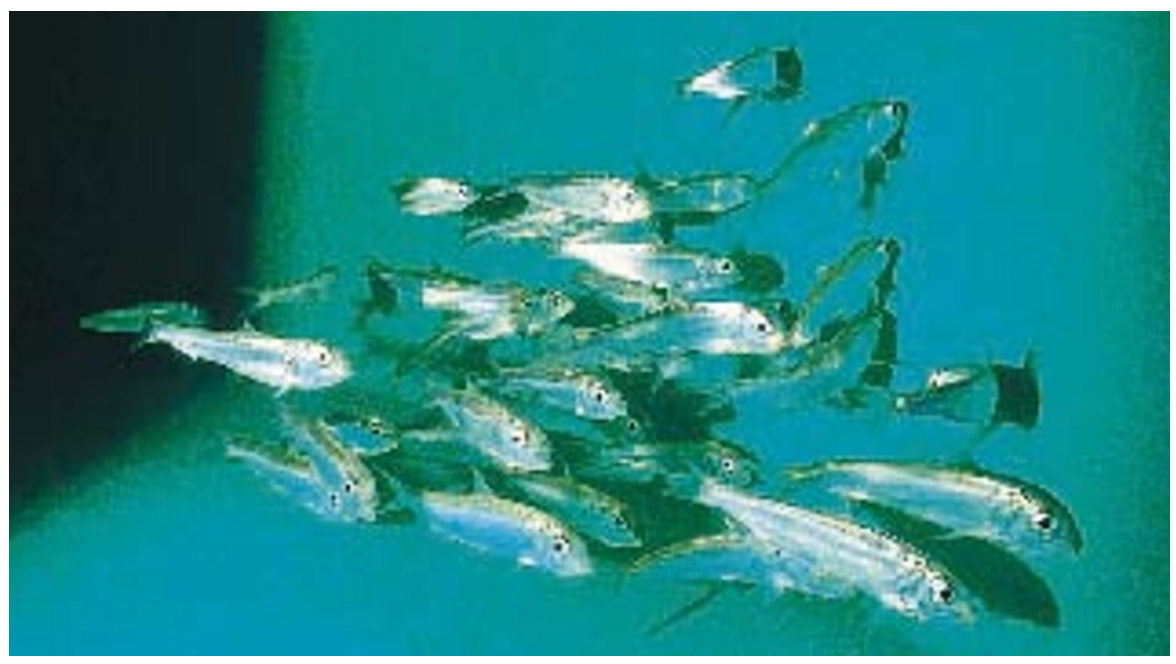

Figure 1 A shoal of American shad, Alosa sapidissima, in their holding tank.

between 3.2 and $12.8 \mathrm{kHz}$. At ultrasonic frequencies $(25-130 \mathrm{kHz})$, the thresholds were about 145 decibels (reference pressure $1 \mu \mathrm{Pa}$ ), with a decrease in sensitivity at 180 $\mathrm{kHz}$. Thus there are two regions of sensitivity for the American shad, one at low frequencies, as is commonly found among fishes, and one at high frequencies, at which most fishes have not previously been tested. The low-frequency thresholds were probably masked by background noise from pumps, and so cannot be considered absolute thresholds. Shad could also detect simulated bottlenose dolphin echolocation clicks, which had a $50-\mu$ s duration, an inter-click interval of $50 \mathrm{~ms}$ and a peak frequency of $80 \mathrm{kHz}$.

To control for the possibility that the shad could have been detecting lowfrequency or electrical artefacts rather than the ultrasound, we trained goldfish to detect a $0.8-\mathrm{kHz}$ tone using the same procedures as for the shad. When the fish had learned to respond at a stable level we tested them with an $80-\mathrm{kHz}$ tone. None of the four fish tested could detect this sound at the highest amplitudes that we could generate $(160 \mathrm{~dB}$, reference pressure $1 \mu \mathrm{Pa})$, indicating that ultrasound detection by the shad was not artefactual.

Ultrasound detection is probably not widely found among fishes, although it has been shown that cod (Gadus morhua) can detect $38-\mathrm{kHz}$ signals ${ }^{6}$. Our results demonstrate a far wider range of ultrasound detection in shad than in cod (which had a poorer threshold than the shad). But, as demonstrated by the goldfish, ultrasound detection is not necessarily common even among fishes that hear relatively well at low frequencies.

Clupeiformes have a unique ear structure in which a pair of thin air-filled tubes project from the swimbladder and terminate in air chambers that are connected with the utricles of the inner ear ${ }^{7}$. This may allow the bullae and utricle to be used in ultrasonic hearing, although there is no evidence to show how this might take place.

The ability of clupeids to detect ultrasound may be an example of convergent evolution with moths and other insects which also have auditory systems capable of detecting the ultrasonic sounds of predators ${ }^{8}$. Shad readily detect echolocating pulses of dolphins, and, like moths, the response to the detection of such sounds is escape behaviour. It is possible that the ability of clupeids to detect ultrasound is a preadaptation that evolved before there were echolocating predators. All extant clupeids share the auditory specializations of the ear, and fossil clupeids are known from the Lower Cretaceous period (130 million years ago), long before odontocete cetaceans evolved in the Oligocene epoch (25-38 million years ago $)^{9,10}$.

\section{David A. Mann, Zhongmin Lu}

\section{Arthur N. Popper}

Department of Zoology, University of Maryland,

College Park, Maryland 20742-4415, USA

e-mail:Popper@zool.umd.edu

1. Fay, R. R. Hearing in Vertebrates: A Psychophysics Databook (Hill-Fay Assoc., Winnetka, Illinois, 1988).

2. Au, W. W. L. The Sonar of Dolphins (Springer, New York, 1993). 3. Nestler, J. M., Ploskey, G. R., Pickens, J., Menezes, J. \& Schilt, C. N. Am. J. Fish. Man. 12, 667-683 (1992).

4. Ross, Q. E. \& Dunning, D. J. N. Am. J. Fish. Man. 16, 548-559 (1996).

5. Lu, Z., Popper, A. N. \& Fay, R. R. J. Comp. Physiol. A 179, 227-233 (1996).

6. Astrup, J. \& Møhl, B. J. Exp. Biol. 182, 71-80 (1993).

7. Blaxter, J. H. S., Denton, E. J. \& Gray, J. A. B. in Hearing and Sound Communication in Fishes (eds Tavolga, W. N., Popper, A. N. \& Fay, R. R.) 39-59 (Springer, New York, 1981).

8. Roeder, K. D. Anim. Behav. 10, 300-304 (1962).

9. Nelson, J. S. Fishes of the World (Wiley, New York, 1994).

10. Barnes, L. G., Domning, D. P. \& Ray, C. E. Mar. Mam. Sci. 1, 15-53 (1985). 